\title{
Assessment of Stability and Energy Dissipation Performances of an Antifer Layer Protected Caisson
}

\author{
Dursun Zafer Şeker $^{1^{*}}$, M. Sedat Kabdaşıı ${ }^{2}$, Murat Çelikoyan ${ }^{1}$ and Cem \\ Gazioğlu ${ }^{3}$
}

\author{
${ }^{1}$ Istanbul Technical University, Civil Eng'g Fac., Dept. of Geomatics Eng'g, 34469, MASLAK ISTANBUL,TR \\ ${ }^{2}$ Istanbul Technical University, Civil Eng'g Fac. Dept. of Civil Eng'g, 34469, MASLAK ISTANBUL, TR \\ ${ }^{3}$ İstanbul University, Institute of Marine Sciences and Management, 34134, VEFA FATIH, ISTANBUL, TR
}

\begin{abstract}
The present study intends to assess the stability and energy dissipation performances of a breakwater configuration (APC) protected by an antifer layer. For comparison, an ordinary caisson (OC), which was 5\% wider and $10 \%$ heavier, was also investigated. Physical models were implemented and tested under regular and irregular waves; and resulting linear and angular displacements were directly measured via a photogrammetric method. Additionally, wave forces and resulting horizontal displacements were estimated both from recorded pressure data and from individual incident waves by modified Goda method. To calculate the horizontal displacement, the estimated wave force time series were directly double-integrated, whilst the theoretical method proposed by Shimosako et al. (1994) were used on the individual force values. Although OC was tested under shorter durations and had a more favorable superstructure in terms of resisting forces, the results indicated that APC was significantly more stable. Energy dissipation performance of the tested configurations were quantified in terms of spectral averaged and phase resolved reflection coefficients, whereas antifer damage ratio was measured on a block-count basis. Results indicated that the APC configuration had an enhanced performance of dissipating the wave energy; moreover, the dissipated energy directly links to antifer damage ratio.
\end{abstract}

Keywords: Antifer protected caisson, Caisson displacements, Stability performance, Damage ratio, Wave energy dissipation

\section{Introduction}

Although sloped structures, namely rubble mound breakwaters, are primarily preferred for coastal protection, caisson type breakwaters can sometimes be superior alternatives especially when the construction location is too deep or instantly steepening, or simply because natural armor blocks are scarce or relatively expensive. The constant breadth of caissons can also serve for berthing purposes at the landward side. Such a structure would resist against the massive wave load (force or moment) with only its weight, instead of impelling the wave to dissipate its energy on a slope (Goda, 1985).
This causes the caissons to be exerted high impact loads if the incident wave is breaking, or leads excessive reflection in non-breaking case.

Many different techniques have been applied to overcome these weaknesses of caisson type breakwaters. Construction of a rubble mound berm just in front of the caisson is a common engineering application that would not only hinder any unbroken waves higher than the design wave, but also prevent the design wave to break just on the vertical face of the caisson. For further enhancement of structure performance by causing wave dissipation regardless of incident wave properties, the crest 
elevation of this protective berm can be increased with artificial blocks up to or over the mean sea level (MSL), such that a protective rubble-mound cover is maintained for the monolithic structure. Takahashi et al. (1990) investigated the wave loads on a caisson protected by such a rubble-mound structure composed of artificial blocks (CEM, 2006 p. VI-5-142). According to their experimental data they proposed some reduction factors to be used in wave force calculations. Liu et al. (1999) studied how the flow in front of a caisson was enhanced and to what level overtopping could be limited by using such a high layer of protective armor units. They used a numerical model to determine the interaction of incident waves with the fronting porous structure, basically solving Reynolds averaged Navier-Stokes equations coupling with a k- $\square$ model. Comparing their results with laboratory data, they concluded that such a protective cover helps to dissipate the energy of incident waves. Later, Sakakiyama and Liu (2001) experimentally investigated the flow in front of and the pressures on a caisson protected by a high layer of tetrapod blocks. Their major conclusion was that turbulence was generated inside the protective armor layer and transported into the flow region in front of the breakwater. The impact pressure heads they had recorded reached up to 1.85 times of wave height.

On the other hand, the fundamental structural performance criterion for a caisson breakwater would be the linear (and secondarily angular) displacement, as can be expected in any monolithic structure case (Shimosako and Takahashi, 1999). Many investigations have been carried out to quantify the transition and rotation of caisson body as a result of impact loads generated by breaking waves. A massspring constant analogy is one of the suggested models to explain the transition and rotation, including elastic displacements (Oumeraci and Kortenhaus, 1994). Goda (1994), Shimosako and Takahashi (1994), Kim and Takayama (2003) tried to model the dynamic reaction of a caisson against impact pressure and accordingly suggested models to calculate the linear displacement. Shimosako and Takahashi (1999) and Ling et al. (1999) proposed a design methodology based on the permanent displacement of a caisson instead of the classical factor of safety approach. They evaluated the horizontal displacements based on a yield wave load basis. Ling et al. (1999) assumed a sinusoidal variation of both horizontal force and uplift, comparing their method with 35 case histories whereas Shimosako et al. (1994) considered a linearly rising and falling impact force superposed with the sinusoidal variation of non-breaking component, as will be detailed herein. Later, Wang et al. (2004) and Wang et al. (2006) developed more complex analytical and numerical models to simulate initiation of transition together with rotation (further than the simple transition) with regard to the structure-bed friction conditions. They also compared their results with some physical model data.

In this study, structural performance of a composite caisson breakwater protected by a fronting layer of antifer blocks was physically tested under regular and irregular waves from the wave impact and displacement points of view. The purpose of the study is not to come up with a design formula for antifer protected caissons, but rather to demonstrate the introduced enhancement in the performance of the structure compared to an ordinary caisson. The crest elevation of antifer layer was set to be at MSL. In order to assess the effect of antifer layer on caisson stability, an ordinary caisson (without antifer cubes) was also tested. Both of the configurations had similar bedding conditions, but the latter was approximately 5\% wider and $10 \%$ heavier with a different superstructure (crown-wall and coping slab). The linear (in-line and vertical) and angular displacements of caisson bodies were measured via a multipoint-based photogrammetric technique, details of which are explained in this paper, while the antifer damage was determined on a block-count basis (Yagci et. al., 2004). Wave forces were estimated using the pressure data recorded by independently placed pressure transducers on the frontface of the caisson, as was done in Kirca and Kabdasli (2009). Furthermore, the individual zero-crossed waves obtained from a spectral decomposition algorithm (Kirca, 2008)) and inverse Fourier transform (wave height and period couples) were used to estimate the maximal individual 
wave forces as per modified Goda approach by Takahashi et al. (1994).

Horizontal displacements of caissons were evaluated by two additional approaches besides the directly measured values. First of them was double integration of the wave force time series estimated from pressure data. The second evaluation was performed by employing the semi-empirical methodology proposed by Shimosako et al. (1994) to estimate the horizontal displacements from maximal individual wave forces (Takahashi et al., 1990; Takahashi et al., 1994). Results indicated that the tested protective antifer layer introduces a significant stability enhancement in terms of cumulative horizontal caisson displacements per unit economic lifetime.

In addition to stability assessment, service energy dissipation- performance of the tested breakwater configurations is also presented in terms of reflection coefficients and some observations/qualitative evaluations on wave overtopping. A considerable reduction was seen in reflection and wave overtopping.

Earlier results of this study was presented at the 23rd International Offshore and Polar Engineering conference held in Anchorage, Alaska, USA (Kirca et al., 2013).

\section{Study Area Physical Modeling Model Characteristics}

The tests were carried out in a $1 \mathrm{~m} \times 1 \mathrm{~m} \times 24$ $\mathrm{m}$ dimensioned wave flume located in Hydraulics laboratory of Istanbul Technical University, Civil Engineering Faculty (Figure 1). The flume is glass walled and equipped with a flap type irregular wave generator.

Model caisson units were built by composing different materials as shown in Figure 2. The caisson bodies were made of wood instead of concrete; considering the easiness of construction, robustness against cracking and easier fitting of the pressure transducers. The superstructure of the caisson units (crown-wall and coping slab), however, were cast of reinforced concrete and fixed to the body by means of screwed tying rods (Figure 2). Beforehand, a sand and lead mixture was uniformly placed in these wooden boxes in order to satisfy a reasonable weight considering testing conditions. The submerged weights of the antifer layer protected caisson (APC) and ordinary caisson $(\mathrm{OC})$ were $\mathrm{W}^{\prime} \mathrm{APC}=1434$ $\mathrm{N} / \mathrm{m}$ and $\mathrm{W}^{\prime} \mathrm{OC}=1580 \mathrm{~N} / \mathrm{m}$, respectively. It will be convenient to note that these values are approximately $8 \%$ less than the weights of idealized prototype caissons that would have similar dimensional properties. In addition to this, the friction factor between model caissonfoundation were supposed to be less than prototype conditions since the bottom surfaces of model caissons were not concrete, but plain wood (friction factor issue is further discussed below). Thus, the modeling study can said to be conservative in terms of resisting forces.

A $97 \mathrm{~cm}$ long segment of the breakwater was represented with the model, leaving gaps of ca. $1.5 \mathrm{~cm}$ between the flume walls and the model caisson from each side. Such a configuration prevented the contact between the glass side walls and the caisson body. Later, the gaps were sealed with nylon strips (without gluing) from the seaward side of the model, so that the two-dimensional nature of the model would not be affected by energy flux from these gaps.

Antifer blocks have a characteristic geometric shape close to a cube, dimensions of which are related to block base width, a (Figure 3). The base width is calculated by the below formula:

$$
a=\left(\frac{W_{\text {antifer }}}{0.8 \gamma_{\text {antifer }}}\right)^{1 / 3}
$$

where Wantifer and $\square$ antifer are the weight and the specific weight of the unit, respectively (among many others, Yagci et al. (2004) can be referred for a detailed account on shape characteristics of antifer cubes). The antifer units used in the present study were cast from plain concrete (no reinforcement elements) and the values of a, Wantifer and $\square$ antifer were $7.51 \mathrm{~cm}, 7.285 \mathrm{~N}$ and $21.5 \mathrm{kN} / \mathrm{m} 3$, respectively. The targeted tolerance of antifer size in the model was $0.006 \%$ in volume $( \pm 2 \mathrm{~cm} 3)$.

The placement technique and placement density of antifer blocks would certainly affect the 
overall stability of the breakwater along with the damage ratio of antifer layer, regarding the interlocking of units and wave energy dissipation efficiency. In this study, the irregular placement that was explained in Yagci et al. (2004) was used. A sample pattern of placement is shown in Figure 3. With this placement, resulting placement density of the blocks was roughly about $60 \%$. Placement density is defined as the ratio of total net antifer volume to the total protection cover volume (i.e. 1-n where $\mathrm{n}$ is the porosity). Total volume of protection cover per unit width is calculated with respect to the bottom elevation $(-16 \mathrm{~cm})$; crest elevation $( \pm 0 \mathrm{~cm})$ and length of protection cover $(53 \mathrm{~cm})$, including an end slope of 2:3 (refer to Figures 5).

To simulate the rubble mound berm and bedding of caisson, rough angular stones were used (Figure 5 and 6). The berms of the caissons were composed of stones with nominal spherical diameters of 4.5 5.7 cm (125 250 grams in mass). For the caisson beddings and part of the berm that underlied antifer cubes, however, this category was $2.6 \sim 4.5 \mathrm{~cm}(25 \sim 125$ grams in mass). The bottom sand was finemedium beach sand with a median nominal diameter of $\mathrm{d} 50=0.20 \mathrm{~mm}$.

Water depth in the wave flume was fixed at 63 $\mathrm{cm}$ throughout the tests. After a 0.08 sand slope along the flume, this depth became $24 \mathrm{~cm}$ at the model breakwater sections, which was simply the construction depth (Figure 1).

\section{Experimental Set-up and Instrumentation}

During the model tests, time series of two main parameters were measured and recorded: wave heights along the flume and wave pressures on the caisson. Video recordings were performed throughout each test and the antifer layer was closely observed to assess the damage ratio.

After each test, the linear and angular displacements of the caisson body relative to the start of that test were measured on the basis of a photogrammetric multipoint-referencing technique (as explained in the relevant subsection).
The wave heights were measured with resistant type wave probes on 4 different points located at different distances from the seaward toe of caisson body: $8.1 \mathrm{~m}, 5.8 \mathrm{~m}, 3.1 \mathrm{~m}$ and $1.1 \mathrm{~m}$, respectively. The data from these probes were transferred to a PC via an A/D card and recorded digitally with $20 \mathrm{~Hz}$ sampling rate.

For the first configuration (caisson with antifer cubes), total 5 piezoelectric pressure transducers, three placed on the caisson body and two placed on the crown-wall, were used to determine the pressure pattern acting on the caisson unit. In the second configuration, the uppermost transducer had to be removed as the applied crown-wall geometry was not suitable. The locations of the transducers with respect to MSL are given in Figures 5 and 6. The data from all transducers were collected by a data logger with a sampling rate of $32 \mathrm{~Hz}$ and transferred to $\mathrm{PC}$ via a control unit.

For the displacement measurements, a Pentax ATS-102 model total station instrument and an Olympus SP-510UZ camera with $6.3 \mathrm{~mm}$ focal length and 7.1 million pixel resolution were employed.

\section{Test Procedure}

As explained above two groups of tests were conducted: The first group with an antifer layer protected caisson configuration (APC) and the second with an ordinary caisson (OC). The sketches of these configurations are shown in Fig. 5 and 6, respectively. As can be seen, OC is wider and taller (thus heavier) than APC. Besides, the crown walls of two configurations have different geometries. This was actually done to decrease the impact loads on and excessive reflection from $\mathrm{OC}$ at the expense of increased overtopping.

The test matrix is given in Table 1. As presented here, 10 wave series were included in the first test group (APC), whereas 7 wave series were used for the second test group (OC). Furthermore, the durations of tests were kept shorter for OC compared to APC (Table 1). The reason of following such a test procedure can be summarized as follows: During the preliminary tests, it was seen that the second configuration, OC, had yielded a significantly 
higher reflection, overtopping and failure at the bedding conditions (e.g. scour, sliding, etc.) which caused extreme displacements compared to APC. Especially in regular waves, the reflections from OC became so severe that the berm in front of the caisson was emerged time to time under the superposed wave trough. This was an undesirable situation for the purpose of the test, since the idea behind this study was to investigate the sliding failure between caisson and underlying bed due to wave impact, rather than dealing with the geotechnical failure modes (For an extensive definition of these modes see Sørensen and Burcharth (2000)). For the sake of testing two configurations on equivalently stable geotechnical basis, shorter wave series and less number of regular wave tests were utilized in the second configuration, so that the net horizontal displacement of both caissons were at the same order of magnitude. Indeed, the measured cumulative horizontal displacements of both APC and OC were seen to be around $2 \mathrm{~mm}$ at the end of the tests, as will be discussed below.

The wave series were applied in the same order as given in Table 1. The first 6 wave series for both configurations were irregular waves. Each pair of these irregular wave series (on APC and OC) were meant to have the same narrow band spectral properties, but with different durations as expressed above. In regular wise, so were APC-10 and OC-7. On the other hand, there was no active wave absorption system installed on the wave palette. This introduced an additional difference between the incident wave spectra of two configurations due to the rereflected waves from the palette since APC generated significantly less reflection than OC (as will be discussed below). These irregular wave series were generated on the basis of Gamma spectrum. A spectral decomposition algorithm, details of which were explained in Kirca (2008), was used to assess the incident and reflected wave characteristics. Data from the farthest two wave probes from the caisson were used for this purpose and the resulting closure error of total wave energy (i.e. the difference between the spectral energies of wave recordings and estimated superposed waves) was less than $1.7 \%$ for all the tests. The decomposed incident and reflected wave spectra of tests labeled APC-06 and OC-06 (see
Table 1) are given in Figure 7 with the targeted Gamma spectrum.

The displacements were measured in a cumulative manner after each test until the end of that test group. The antifer damage ratio for each test was assessed by observing them closely during the tests and applying a movement-type-weighted approach (see section 4.3). Accordingly, no correction or realignment was done for the caisson body, antifer cubes, underlying rubble mound berm or sand bed between successive tests unless the configuration was changed.

\section{Evaluation of Results}

\section{Estimation of Wave Forces from Pressure}

\section{Time Series}

In this method, a direct evaluation of recorded pressure time series data was performed to come up with tentative wave force time series (as done in Kirca and Kabdasli (2009)). Figure 8 gives the fundamentals of assumed pressure exertion pattern on the structure (as originally proposed by Goda (1985)). Note that the pressures on sloped surfaces were decomposed into horizontal and vertical projections.

Given the pressure data from three transducers below MSL (pPT1, pPT2 and pPT3,) simply a linear trend was fit to these three points and extended to MSL $(z=0)$ and to the caisson bottom level $(\mathrm{z}=-25.6 \mathrm{~cm})$. The corresponding pressure values were set to be $\mathrm{p} 1$ and $\mathrm{p} 3$. Under the caisson, a triangular pressure distribution was described which is controlled by the uplift pressure, pu, at the seaward side. Though some amount of dampening (and possibly a time-lag) might be expected especially for the unprotected (OC) case, the uplift force was assumed to be equal to the bottommost pressure value on the frontface ( $\mathrm{pu} \approx \mathrm{p} 3)$. Actually this holds true unless the incident wave starts to break before the berm and just collapses on the caisson (refer to equations (9), (10) and (11); for a rubble-mound protected caisson, Takahashi et al. (1990) suggested pu $\equiv$ p3 as the impulsive component is automatically diminished by the protection layer). 
In addition to horizontal wave force, a vertical component from the frontface of the caisson will appear due to the sloped section of the crown-wall. Simply by projecting this surface segment into horizontal and vertical, the additional vertical force can be evaluated (as done by Tanimoto and Kimura (1985), in CEM (2006) p. VI-5-140). This additional force will

$$
\eta^{*}=\left\{\begin{aligned}
\max \left[\frac{p_{1}}{\gamma},\left(\frac{p_{\mathrm{PT} 4}}{\gamma}+z_{\mathrm{PT} 4}\right),\left(\frac{p_{\mathrm{PT} 5}}{\gamma}+z_{\mathrm{PT} 5}\right)\right], & \Rightarrow p_{\mathrm{PT} 4}>0 \vee p_{\mathrm{PT} 5}>0 \\
\frac{p_{1}}{\gamma} & , \Rightarrow p_{\mathrm{PT} 4} \leq 0 \wedge p_{\mathrm{PT} 5} \leq 0
\end{aligned}\right.
$$

Here $\square$ is the specific weight of the fluid (water) and $\mathrm{z}$ denotes the elevation of transducer with respect to MSL. For OC case, pPT5 term vanishes as there is only one transducer above MSL. If the run-up height is larger than the crest elevation of the caisson (18 $\mathrm{cm})$, the corresponding pressure acting on this elevation, $\mathrm{p} 4$, is calculated from the triangular similarity:

$$
p_{4}=\frac{p_{1}}{\eta^{*}} \cdot \max \left[0,\left(\eta^{*}-0.18\right)\right]
$$

The pressure values p5 and p6, which are necessary to evaluate the vertical component of wave force, are calculated as follows for $\mathrm{OC}$ case: be downward for the $\mathrm{OC}$ case and upward for APC case with regard to the crown-wall geometries (Figure 8).

The wave run-up height, $\eta^{*}$ was estimated as follows:

$$
\begin{aligned}
& p_{6}=\frac{p_{P T 4}\left(\eta^{*}-0.12\right)}{\left(\eta^{*}-0.08\right)} \\
& p_{5}=\frac{p_{P T 4}\left(\eta^{*}-0.06\right)}{\left(\eta^{*}-0.08\right)}
\end{aligned}
$$

For APC case only p6 is to be determined:

$$
p_{6}=p_{P T 5}\left[1+\frac{0.10\left(p_{P T 5}-p_{P T 4}\right)}{\left(p_{P T 4}-0.08 p_{P T 5}\right)}\right]
$$

With these considerations the resulting horizontal wave force, $\mathrm{P}$, vertical wave force, $\mathrm{Pv}$ and uplift force, $\mathrm{U}$, per unit width can be calculated accordingly:

$$
\begin{aligned}
P & =\left(\frac{p_{3}+p_{\mathrm{PT} 1}}{2}\right) \cdot 0.104+\left(\frac{p_{\mathrm{PT} 1}+p_{\mathrm{PT} 2}}{2}\right) \cdot 0.06+\left(\frac{p_{\mathrm{PT} 2}+p_{\mathrm{PT} 3}}{2}\right) \cdot 0.06 \\
& +\left(\frac{p_{\mathrm{PT} 3}+p_{1}}{2}\right) \cdot 0.04+\left(\frac{p_{1}}{2} \cdot \eta^{*}\right)-\left[\frac{p_{4}}{2} \cdot\left(\eta^{*}-0.18\right)\right] \\
P_{v} & =\frac{\left(\left\{p_{5} \vee p_{P T 5}\right\}+p_{6}\right)}{2} \cdot \ell
\end{aligned}
$$

$$
U=\frac{p_{u}}{2} \cdot B
$$


where $\mathrm{B}$ is the breadth of the caisson and $\ell$ is vertical projection of the sloped surface $(6 \mathrm{~cm}$ for OPC and $3 \mathrm{~cm}$ for APC). The wave and uplift forces exerted on the caisson are shown by light blue shaded regions in Figure 8 . It would be convenient to note that the pressure pattern acting on the frontface of the caisson below MSL is not taken as a single trapezoid, but portions of trapezoids between measurement points, as in equation (6a). This was done to account for any probable distortion of the pressure pattern due to antifer cubes in the APC configuration.

Figure 9 shows a sample section from the pressure time series of APC-06 test with the estimated horizontal force.

$\eta^{*}=0.75(1+\cos \beta) \lambda_{1} H_{D}$

$p_{1}=\frac{1}{2}(1+\cos \beta)\left(\lambda_{1} \alpha_{1}+\lambda_{2} \alpha_{*} \cos ^{2} \beta\right) \gamma H_{D}$

$p_{3}=\alpha_{3} p_{1}$

$p_{u}=\frac{1}{2}(1+\cos \beta) \lambda_{3} \alpha_{1} \alpha_{3} \gamma H_{D}$

Here, $\beta$ is the angle of wave incidence (which is 0 for this $2 \mathrm{D}$ case), $\mathrm{h}$ is the global depth at the construction location (Figure 8 ) and HD is

$$
\begin{aligned}
& \alpha_{1}=0.6+\frac{1}{2}\left[\frac{4 \pi h / L}{\sinh (4 \pi h / L)}\right]^{2} \\
& \alpha_{3}=1-\frac{h^{\prime}}{h}\left[1-\frac{1}{\cosh (2 \pi h / L)}\right] \\
& \alpha_{*}=\max \left(\alpha_{2}, \alpha_{\mathrm{I}}\right)
\end{aligned}
$$$$
\alpha_{2}=\min \left\{\frac{h_{b}-d}{3 h_{b}}\left(\frac{H_{D}}{d}\right)^{2}, \frac{2 d}{H_{D}}\right\}
$$ 
$\alpha_{\mathrm{I}}=\alpha_{\mathrm{I} 0} \alpha_{\mathrm{I} 1}$

$\alpha_{\mathrm{I} 0}=\min \left(H_{D} / d, 2.0\right)$

Here $\alpha_{2}$ and $\alpha_{\mathrm{I}}$ represents the effects of breaking wave and impulsive pressure, respectively, whereas $\mathrm{h}^{\prime}$ and $\mathrm{L}$ are the burial

$$
\begin{aligned}
& \alpha_{\mathrm{II}}=\left\{\begin{array}{l}
\cos \delta_{2} / \cosh \delta_{1} \\
1 /\left[\cosh \delta_{1}\left(\cosh \delta_{2}\right)^{0.5}\right] \Rightarrow \delta_{2}<0
\end{array}\right. \\
& \delta_{1}=\left\{\begin{array}{l}
20 \delta_{11} \Rightarrow \delta_{11}<0 \\
15 \delta_{11} \Rightarrow \delta_{11}>0
\end{array}\right.
\end{aligned}
$$$$
\delta_{2}=\left\{\begin{array}{lll}
4.9 \delta_{22} & \Rightarrow & \delta_{22}<0 \\
3.0 \delta_{22} & \Rightarrow & \delta_{22}>0
\end{array}\right.
$$$$
\delta_{11}=0.93\left(B_{M} / L-0.12\right)+0.36[(h-d) / h-0.6]
$$$$
\delta_{22}=-0.36\left(B_{M} / L-0.12\right)+0.93[(h-d) / h-0.6]
$$

As can be seen, the berm geometry controls the impulsive pressure coefficient, namely dimensionless berm breadth $(\mathrm{BM} / \mathrm{L})$ and dimensionless berm depth $(\mathrm{d} / \mathrm{h})$ parameters. The coefficients $\square 1, \square 2$ and $\square 3$ appearing in

$$
\lambda_{1}=\lambda_{3}=\left\{\begin{array}{lll}
1.0 & \Rightarrow & H_{D} / h<0.3 \\
1.2-0.67\left(H_{D} / h\right) & \Rightarrow & 0.6 \geq H_{D} / h \geq 0.3 \\
0.8 & \Rightarrow & H_{D} / h>0.6 \\
\lambda_{2}=0 &
\end{array}\right.
$$

However, the values in equation (20) are given for a situation where the rubble-mound is composed of complex blocks with high interlocking (like Tetrapods or Dolosse) and emerges until the crest elevation of the caisson, unlike the present model.

The vertical component of the wave force, Pv, appearing due to sloped portions of the crown- equation (8), (9) and (11) are equal to unity for an ordinary caisson, whilst given as follows for a protected caisson by rubble-mound structure (Takahashi et al., 1990):

$$
\text { (20b) }
$$

wall can be calculated as in equation (6b) by determining p5 and p6 values from triangular similarity via equations (6) and (7). However, this might not be accurate. It is noteworthy that Takahashi and Hosoyamada had performed model tests on caissons with particular sloping top structures and stated some reduction factors on characteristic wave pressures (CEM, 2006 page VI-5-140). When these factors were included into calculation for the OC case in the 
present study, the wave forces were reduced so significantly that resulting displacements were almost zero. This might be attributed to differences between the configurations tested in the aforementioned and present studies. Instead, no correction was included in the horizontal load components and a correction factor of 0.5 was used in the vertical projection only for both configurations.

In the original formulation, the design wave height, HD, is found by taking the maximum wave height of the wave series (Hmax $\approx 1.8$ $\mathrm{H}^{1} 1 / 3$ ) and transforming it to the construction depth. If the structure is in the surf zone, this value is compared with the maximum randomly breaking wave height, $\mathrm{Hb}$, at a breaker depth, $\mathrm{hb}$. The smaller of these two is taken as HD since no wave higher than $\mathrm{Hb}$ can reach to the structure without breaking. hb, also appearing in equation (15) is the depth at $5 \mathrm{H}^{1 / 3}$ distance seaward of the structure, where $\mathrm{H}^{1 / 3}$ is the significant wave height of the incident wave series. In the context of this study, where wave forces due to individual waves were intended to be evaluated, both $\mathrm{Hmax}$ and $\mathrm{H}^{1} 13$ were replaced with $\mathrm{H}$, the height of individual wave. The following formulation is used:

$$
\begin{aligned}
& H_{D}=\min \left(H_{b}, H^{\prime}\right) \\
& H^{\prime}=K_{s} H
\end{aligned}
$$

$$
K_{s}=\frac{\sqrt{\tanh \left(k_{w g} h_{w g}\right)+\left(k_{w g} h_{w g}\right)\left(1-\tanh ^{2}\left(k_{w g} h_{w g}\right)\right)}}{\sqrt{\tanh k h+k h\left(1-\tanh ^{2} k h\right)}}
$$

where $\mathrm{Ks}$ is the shoaling coefficient due to linear wave theory between the depth of wave generator (hwg) and construction depth (h), $\mathrm{k}=$ $2 \pi / \mathrm{L}$ is the wave number that is found from To calculate the breaker height, $\mathrm{Hb}$, wave breaking formula proposed by Goda (2010) for regular waves was used. dispersion relation at the related depth.

$$
H_{b}=0.17 L_{0}\left\{1-\exp \left[-1.5 \frac{\pi h_{b}}{L_{0}}\left(1+11 s^{4 / 3}\right)\right]\right\}
$$

Here, L0 is the deep water wave length and s is the bottom slope (which is 0.08 for the present case).

After these steps, the maximum horizontal force, vertical force and maximum uplift per unit width for each individual wave can be calculated by the convenient forms of equations (6) and (7). With the method summarized above;

Wave forces on OC were evaluated with $\lambda 1=$ $\lambda 2=\lambda 3=1$ (Figure 10a),

Wave forces on APC were evaluated taking $\lambda 1$, $\lambda 2$ and $\lambda 3$ as in equation (20) (Figure 10b),
Wave forces on APC were evaluated with $\lambda 1=$ $\lambda 2=\lambda 3=1$, for the purpose of comparison with (a) (Figure 10b).

In order to be able to compare the wave forces estimated from pressure time series and estimated from individual waves, a zeroupcrossing process was applied to the former, yielding one value per period. Then these two were plotted versus their cumulative frequencies (or exceedence probabilities) calculated simply by $\mathrm{Cf}=\mathrm{n} /(\mathrm{N}+1)$ for the $n$th wave force value within $\mathrm{N}$ values. The results are shown in Figure 10 separately for OC05/OC-06 tests combined and for APC05/APC-06 tests combined. These pairs of tests were thought to be representative as they yield the maximal wave forces. 
For OC, wave forces estimated from both methods can said to be compatible within a difference range of $10 \%$ (Figure 10a). For $\mathrm{Cf}$ $<0.015$ this difference might be significant from the resulting displacements point of view as the highest wave forces are effective to decide on the ultimate displacement.

For APC case, there is a third curve which shows the effect of a rubble-mound protection formed from interlocking blocks that would emerge up to the crest elevation of the caisson (as described by Takahashi et al. (1990)). Figure $10 \mathrm{~b}$ clearly shows that for lower waves $(\mathrm{Cf}>0.35)$ there is not much modification with the introduction of such a rubble mound structure whilst for higher waves $(\mathrm{Cf}<0.35)$ it would hinder the wave forces on the caisson very effectively. This is not surprising since the latter method, by definition, assumes that such a high and intricate rubble-mound protection becomes more and more effective as waves grow higher (equation (20a) ) and prevents the waves to break on the structure (equation (20b) ). The wave forces estimated from pressure time series (dashed curve in Figure 10b) almost overlaps the wave forces estimated from individual waves for no-protection case when Cf $>0.005$, however stays more or less constant for $\mathrm{Cf}<0.005$ and thus diverges from the latter. This highest $1 / 200$ portion of wave forces would most probably act as impulsive forces on an unprotected vertical structure that were represented by the $\square$ I coefficient proposed by Takahashi et al. (1994) (see equations (16)(19)). The antifer protection modeled in the present study is obviously expected to introduce a certain reduction in the wave force, but apparently not as much as the former proposed by Takahashi et al. (1990). It would be useful to mark this statement, as will be discussed later on.

To give a clearer picture, it would be convenient to report the safety factors against sliding, SF, for each configuration, which would be defined as follows.

$$
S F=\frac{\mu\left(W^{\prime}-U-P_{v}\right)}{P}=\frac{F_{f}}{P}
$$

where $\mu$ is the friction factor between the caisson bottom surfaces-bedding and $\mathrm{Ff}$ is the friction force. Naturally $\mu$ is a measure of the adhesion resistance between the contact surfaces. For a concrete surface resting on clean coarse bedding material (a typical prototype caisson case) it is mostly taken at the order of 0.60 . For the present modeling study, friction factor between plain-finished wood and clean coarse bedding is to be used. Although no clear value for this parameter is found in the literature, NAVFAC DM7-02 (1986) recommends 0.50 for masonary on wood. Thus, $\mu=0.45$ was adopted in the calculations. In equation (25), the sign of $\mathrm{Pv}$ will be negative for OC case, which will work in favor of resisting forces and opposite for APC. For a design storm of $\mathrm{H}^{1 / 3}=12.8 \mathrm{~cm}$ and $\mathrm{T}^{1} / 3=2 \mathrm{~s}$, SF values would be 0.99 and 1.04 for APC and OC, respectively taking $\lambda 1=\lambda 2=\lambda 3=1$. When these coefficients are adjusted as per equations (20) considering a relevant rubblemound protection, indeed, the factor of safety against sliding for APC rises to 1.57. This modification is due to the $\lambda 1, \lambda 2$ and $\lambda 3$ coefficients, which make the breaking wave or impulsive pressure contribution zero as well as decreasing the non-breaking wave force (equations (9) and (20) ), as stated above.

Once the wave forces in (a), (b) and (c) above were estimated, these results would be processed to evaluate the horizontal displacement of the caissons with the below explained methodology.

Equation of Motion and Dynamic Considerations for Caisson Displacement

Excluding all the geotechnical failure modes of the foundation, the caisson will stay stationary unless the wave force, $\mathrm{P}$, exceeds the friction force between the rubble mound bedding and caisson body, Ff (i.e. SF >1). If this happens, the net force, $\mathrm{P}-\mathrm{Ff}$, will accelerate the caisson inversely proportional to its total mass including added mass $(\mathrm{m}+\mathrm{m}$ '). Ignoring secondary effects such as retractable displacements (mass-spring constant), fluid/structural/mechanical damping, etc., the equation of motion of caisson in $\mathrm{x}$ axis (Figure 4) will read as follows: 


$$
a=\frac{d^{2} X}{d t^{2}}=\left\{\begin{array}{cl}
\frac{P-F_{f}}{\left(m+m^{\prime}\right)} & \Rightarrow|P|>\left|F_{f}\right| \vee|V|>0 \\
0 & \Rightarrow|P| \leq\left|F_{f}\right| \wedge|V|=0
\end{array}\right.
$$

Here $\mathrm{X}$ is the displacement of the caisson body, $\mathrm{V}=\mathrm{dX} / \mathrm{dt}$ is the velocity and $\mathrm{a}$ is the acceleration/deceleration term, both of which are vector quantities and can be directionalized as positive or negative along one dimension. As $\mathrm{P}$ will be positive under wave crest and negative under wave trough, the sign of the net force can be both ways and accordingly defines, also, the direction of displacement. However, the wave force time series derived from pressure recordings do not contain any seaward directed force that is strong enough for a negative acceleration. This is, somehow, expected. Goda (1967) stated that unless h/L $>0.25$ is satisfied, seaward directed maxima would not be expected to exceed landward directed maxima in the wave force time series. In the modeled cases, these short waves cannot generate enough wave force to accelerate the caisson. On the other hand, many cases were reported in the literature where caissons had seen to displace towards sea (Oumeraci, 1994). Although there are many discussions on the issue a vast majority were attributed to geotechnical issues. However, there are also theories to explain the phenomena to trappedair issues especially on the landward face of the caisson, due to overtopping (Walkden et al., 2001). For overtopping waves, a certain positive pressure that would exert the landward side of the caisson is also known to generate seaward directed forces. Yet, no pressure sensor was used on the landward side of the caisson which could record any such case during the tests.

The added mass, the mass of surrounding fluid (water) per unit width that will also be accelerated simultaneously with the caisson, was approximated as (Shimosako and Takahashi, 1999; Goda, 2008):

$$
m^{\prime} \cong 1.086 \rho h^{\prime 2}
$$

where $\rho$ is the specific mass of fluid (water). When equation (26) is double-integrated, the horizontal displacement can be found. With the estimated time series of wave forces (as in Figure 9), this was done. To increase the temporal resolution of the process, time series were interpolated to $50 \mathrm{~Hz}$. Figure 11 presents a sample time series of estimated horizontal wave force along with the magnitude of friction force and corresponding calculated acceleration, velocity and displacement. As can be seen here, the caisson body starts to accelerate immediately once the horizontal wave force overwhelms the friction, and decelerates with the takeover of friction again.

Figure 12 represents the theoretical simplified model suggested by Shimosako et al. (1994), applied to the time series data given in Figure 11. They proposed a model that superposes a wave period related sinusoidal wave force and a triangular impulsive component that would impact in a shorter duration. The peak of the former is defined by the $\alpha 1$ coefficient only, whereas the latter is characterized by both $\alpha 1$ and $\alpha^{*}$ (equation 9). Likewise, the uplift force, $\mathrm{U}$, will act simultaneously as a sinusoidal slowly varying component superimposed with a triangular pulse characterized with a timescale $\alpha 0$. This timescale was also defined by the impulsive pressure component $\alpha^{*}$, proportional with T.

$\tau_{0}=k \tau_{0 F}$

$k=\left(\frac{1}{\left(\alpha^{*}\right)^{0.3}+1}\right)^{2}$ 


$$
\tau_{0 F}=\left\{\begin{aligned}
\left(0.5-\frac{H}{8 h}\right) T & \Rightarrow \frac{H}{h} \leq 0.8 \\
0.4 T & \Rightarrow \frac{H}{h}>0.8
\end{aligned}\right.
$$

$(28 c)$

In the original formulation, $\mathrm{Pv}$ was not included since no sloped portion of frontface was considered. As was done for $\mathrm{P}, \mathrm{Pv}$ was also represented by a superposed pattern which had two different peaks proportional with $(\alpha 1+$ $\alpha^{*}$ ) and $\alpha 1$, respectively.

As can be seen from Figure 12, the model can satisfactorily represent the shape and exertion pattern of wave force as a function of time. In the present study, the resulting displacement per an individual wave was calculated numerically by double integrating the acceleration term in equation (26) with the aforementioned considerations, since this superposed time series would be complex to integrate analytically. For the triangular impulsive component only, such an analytical solution for resulting displacement was stated as follows (Goda, 2008):

$$
X=\frac{\tau_{0}^{2}\left[F_{s}-\mu W^{\prime}\right]^{3}\left[F_{s}+\mu W^{\prime}\right]}{8 f\left(m+m^{\prime}\right) W^{\prime} F_{s}^{2}}
$$

where Fs is given by:

$$
F_{s}=P+\mu\left(P_{v}+U\right)
$$

\section{Photogrammetric Multipoint Referencing Technique}

To define the displacement of the caisson body via this technique, first a coordinate system was defined for the initial conditions of each tested configuration, using the total station and several reference points both on the flume (fixed points) and on the caisson body (movable points) as shown in Figure 1. After each test, these control points were taken as basis and the movable control points were re-addressed to find the linear transition they were exerted. The re-addressing was done by using oriented camera images. Then the location of the whole body was evaluated by means of transitional and rotational displacement on six degrees of freedom, using the vector-averaged values of these displacements. To be consistent with twodimensional modeling nature of a wave flume, only three of them are evaluated, namely linear along $\mathrm{x}$, linear along $\mathrm{z}$ and angular around $\mathrm{y}$; with reference to the sign convention presented in Figure 4. Note that all measured displacements are given with respect to the middle-bottom point of the caisson.

Pictran software was used for photogrammetric evaluation. It is a modular system which consists of modules for manual measurement, bundle adjustment, ortho-photo production, automatic measurement and digital image rectification. In this study, manual measurement and bundle adjustment modules were used for three dimensional photogrammetric evaluations.

The angular displacement was calculated considering the coplanar movable control points that were placed on the top surface of the caisson body. As these points define a plane, the rotation of this plane around $y$ axis can easily be evaluated.

In the process of evaluating the resultant displacement vector, marginal data points were discarded. Consequently, the measurement errors for linear and angular calculations were kept at the order of $15 \%$ and $10 \%$, respectively.

Furthermore, close observations were made during the tests to see if there was any visible displacement. It was seen that a certain amount of displacement could be distinguished with naked eye. Most of these displacements, however, were retracted right after the driving wave had impacted, which led to almost zero absolute displacement.

\section{Stability and Service Performance Calculated and Measured Displacements}

Like stated above, besides the directly measured values, cumulative horizontal displacements of OC and APC configurations 
were also calculated using previously explained methods. Figure 13 gives the results of these analyses for OC case. The cumulative vertical and angular displacements for $\mathrm{OC}$, on the other hand, are given in Figure 14 (refer to Figure 4 for sign convention). As can be seen from Figure 13, measured values and calculated values are quite in agreement. A strong seaward displacement is seen at OC-03, which co-exists with a tilting of the caisson, restoring towards landside after OC-02 that can be seen from Figure 14.

The vertical displacements are very small during irregular wave tests and suddenly a settlement occurs, possibly by the harmonic effect of regular waves at the last test. For the sake of giving an idea to the reader, a prototype caisson subjected to similar wave properties at similar depth would have possibly been larger by a geometrical scale around 30 . This yields a total horizontal displacement of $6 \mathrm{~cm}$ and a settlement around $2.5 \mathrm{~cm}$. Considering that the limit horizontal displacement of a caisson was set to be $30 \mathrm{~cm}$ as a performance criterion by Shimosako and Takahashi (1999), this prototype caisson can said to have fulfilled about one fifth of its economic lifetime after these 7 tests.

Next come the displacement results of APC case in Figure 15 and 16. Figure 15 presents four curves of cumulative horizontal displacement, three of which are similarly evaluated as in OC case. There is one additional curve that gives the results evaluated after the modification of $\lambda 1, \lambda 2$ and $\lambda 3$ as per equation (20). As expected, the displacement estimated from individual waves for an unprotected caisson $(\lambda 1=\lambda 2=\lambda 3)$ are much higher (approximately by factor 4) whereas the displacements measured and estimated from pressure time series are quite in agreement. On the other hand, the modified $\lambda 1, \lambda 2$ and $\lambda 3$ coefficients as per equation (20) so underestimates the horizontal displacements that they are almost zero. Likewise, this is not surprising as explained above, once again referring to Figure $10 \mathrm{~b}$.

One interesting point is the negative horizontal (seaward) displacement happened in APC-03 coexisting with a landside directed tilting (Figure 16). This is almost identical with the results of OC-03 case. These two tests have the same peak period $(\mathrm{T} p=1.12 \mathrm{~s})$ and thus the same wave length $(h / L p=0.16)$ with each other. Although not clear, a probable explanation can be that this dispersion character might be resulting in a wave breaking pattern that generates landward tilting and seaward displacement.

In Figure 16, the vertical displacements seem to be uniformly downward, pointing out a continuous settlement of the caisson body with an ultimate value of $\mathrm{Z}=-1 \mathrm{~mm}$. It would be convenient to note that the ultimate displacements are at the same order of magnitude both for OC and APC.

Evaluation of Wave Dissipation Performance

The term wave dissipation is used here to address the issues associated with the conditions during the service lifetime of the main facility rather than stability issues although otherwise can be valid. An example would the reflection problem in front of the breakwater for navigating small vessels or splashing issue for the yachts that could be moored at the back side. In the present study the emphasis will be on reflection. The reflection coefficient is defined as follows (Kirca, 2008):

$$
K_{r}=\sqrt{\frac{\int_{0}^{\infty} S_{r}(\omega) d \omega}{\int_{0}^{\infty} S_{i}(\omega) d \omega}}=\sqrt{\iint_{0}^{\infty}\left[K_{r n}(\omega)\right]^{2} d \omega}
$$

$K_{r n}(\omega)=\frac{S_{r}(\omega)}{S_{i}(\omega)}$

where $\mathrm{Si}$ and $\mathrm{Sr}$ are the incident and reflected wave spectra, respectively (Figure 7). This will be expected to reduce to the well known $\mathrm{Kr}=$ $\mathrm{Hr} / \mathrm{H}$ relation for regular waves. In analogy to this simpler form, the phase dependent form of reflection coefficient, $\mathrm{Krn}$, is also defined in 
equation (31). Figure 17 presents reflection coefficients of the tested configurations as a function of wave steepness, $\mathrm{Hs} / \mathrm{Lp}$, where $\mathrm{Lp}$ is the wave length associated with the peak period. As can be seen from this figure, the dependence on wave steepness is rather week for the tested range of wave parameters. It is remarkable, yet not surprising, that the performance of APC is superior compared to OC thanks to the enhanced energy dissipation on (i.e. wave breaking) and in-between (turbulence generation) the antifer blocks.

Figure 18 shows the phase resolved reflection coefficients versus wave period for APC-06 and OC-06 tests. This figure can roughly divided into two: First part is the high frequency components where $\mathrm{T}$ is less than $1 \mathrm{~s}$. This portion has highly scattered reflection coefficients which are generally above 0.7 and more or less equal for APC and OC. The second region consists of low frequency components which have relatively higher spectral energy $(\mathrm{T}>1 \mathrm{~s})$. This part of the spectrum is much ordered and has smaller reflection coefficients. The apparent reason for this is that systematically breaking waves mostly belong to this part. Due to conservation of energy, the more energy is dissipated through breaking, the less reflection occurs. Indeed, the period value where minimum reflection occurs is the peak period. Also with this figure, the superior reflection performance of the antifer protected configuration can be seen once again.

In addition to the explained reflection analysis, a prismatic pan $(10 \mathrm{~cm} \times 10 \mathrm{~cm} \times 97 \mathrm{~cm})$ was placed behind the model across the flume in order to conduct a tentative measurement of the overtopping rate, but could only be used in the antifer protected case. The pan was not fixed to the caisson bodies and a correction factor was used to account for the spilled fraction. Although some measurements were made to find the overtopping rate for both configurations, it was succeeded only for APC case since the overtopping pan was quickly filled in OC case. In this manner, a tentative estimate would be that the overtopping rate for OC (overpassed volume per unit length per unit time) is estimated to be 20-30 times more than that of APC comparing the OC-06 and APC-06 tests. This must also be related to the crownwall configurations since the former had a backward sloping crown-wall to decrease the exerted wave forces at the expense of overtopping.

\section{Description of Antifer Damage Ratio}

For the aforementioned block-count damage ratio, three different types of block movement were considered and it was assumed that each type has different contribution to damage (Yagci et al., 2004). These are as follows:

1) When blocks move under the effect of the incident wave but stay in their initial location (rocking), there is a risk of crack formation considering field conditions. Thus, the contribution of such blocks to total damage is assumed to be $25 \%$ due to the potential damage.

2) If a block leaves its position and displaces a distance shorter than its nominal diameter (turning), it may be more or less stable in its new position compared to the initial one. Anyhow, the surrounding blocks would be affected. Thus, the contribution of a turned block to total damage is assumed to be $50 \%$.

3) If a block is displaced more than one nominal diameter (rolling), it will lose its function totally. Furthermore, surrounding blocks in the vicinity of its initial position will be affected. Hence, such a case is assumed to be full damage $(100 \%)$ for the block.

The resulting damage ratio will be:

$\mathrm{DR}=(0.25 \mathrm{RBN}+0.50 \mathrm{TBN}+1.00 \mathrm{RLBN}) / \mathrm{N}$

where RBN, TBN and RLBN are the rocking, turning and rolling block number respectively. DR is the damage ratio of antifer cover and $\mathrm{N}$ is the total number of blocks.
The damage ratio, DR, of irregular placed loose antifer blocks, which have a certain freedom of movement and restoring capacity to a degree, would be expected to be proportional to the total dissipated wave energy during a test run. 
This can be formulated representatively as follows in SI units of joules $/ \mathrm{m}$.

$$
E_{\text {dis }}=\left(1-K_{r}^{2}\right) \gamma H_{S}^{2} L_{p} \frac{1}{8 T}
$$

Figure 19 presents the dissipated energy versus damage ratio. As can be seen, there is a very significant linear trend except two points which belong to regular waves tests. It is well known that regular waves can cause very high or very low damage compared to irregular waves depending whether they are breaking or not. Irregular waves, on the other hand, could have a breaking and a non-breaking fraction of waves (as explained referring to Figure 18). As a final note, damage ratio below $2 \%$ is generally accepted as no damage (Yagci et al., 2004).

\section{Tentative Adjustment of Wave Force Calculations}

It should be possible to adjust the breakwater type coefficients $(\lambda 1, \lambda 2$ and $\lambda 3)$ appearing in equation (8), (9) and (11) so that the presently tested configuration can be represented with enough accuracy. Referring to Figures 10 and 15 and considering that equation (20a) is valid for highly interlocking complex blocks, it is obvious that larger values should be assigned to $\lambda 1$ and $\lambda 3$ for the APC caisson. On the other, the impulsive component would not be diminished above the MSL due to the crest elevation of antifer layer. Thus, the following tentative adjustments are proposed herein as an example to account for the effect of a protection layer composed of antifer blocks as in APC (Figure 5):

$$
\lambda_{1}=\lambda_{3}=\left\{\begin{array}{lll}
1.0 & \Rightarrow & H_{D} / h<0.3 \\
1.1-\frac{\left(H_{D} / h\right)}{3} & \Rightarrow & 0.6 \geq H_{D} / h \geq 0.3 \\
0.90 & \Rightarrow & H_{D} / h>0.6
\end{array}\right.
$$

$$
\lambda_{2}=\left\{\begin{array}{lll}
0.5 & \Rightarrow & z>h^{\prime} \\
0 & \Rightarrow & z \leq h^{\prime}
\end{array}\right.
$$

where $\mathrm{z}$ is defined in Figure 4. With this modification Figure 15 is reproduced, replacing the relevant curve and presented in Figure 20. As can be seen, the adjusted cumulative displacement values became in better agreement with measured and calculated values from time series. The resulting SF value found from the results of this adjustment for the previously considered design wave $\left(\mathrm{H}^{1} / 3=12.8\right.$ $\mathrm{cm}$ and $\mathrm{T}^{1} / 3=2 \mathrm{~s}$ ) comes out to be 1.23 .

\section{Conclusion and Final Remarks}

In this study, a caisson breakwater configuration (APC) which was protected by an antifer protection layer with a crest elevation at the MSL was tested under 6 irregular and 4 regular wave series in order to assess the stability performance together with wave energy dissipation performance. With this breakwater section, also an ordinary caisson section (OC), which was 5\% wider and $10 \%$ heavier than APC, was tested under same 6 irregular and 1 regular wave series. Furthermore, the latter configuration had a favorable crown-wall configuration to increase frictional forces whereas the former was exposed to additional upward directed wave force component due to its forward sloped crown-wall. The OC was tested under shorter durations in order not to encounter with geotechnical failure modes since only displacements due to wave loads are concerns of the present study. As expected, the resulting displacements were at the same orders of magnitude. Namely, comparison was made on cumulative horizontal caisson displacements 
per unit economic lifetime basis. In addition to the directly measured values, displacements were calculated both by double integrating the wave force time series estimated from pressure recordings and applying the theoretical method of Shimosako et al. (1994) to the wave forces obtained from individual waves decomposed from the superposed wave recordings.

The calculated and measured results agreed quite well, provided that the breakwater-type coefficients $\left(\lambda 1, \lambda_{2}\right.$ and $\left.\lambda_{3}\right)$ in the Takahashi et al. (1994) formulae were adjusted properly for APC configuration. In this aspect, tentative values for $\lambda 1, \lambda 2$ and $\lambda 3$ coefficients are suggested for a caisson protected by irregularly placed antifer layer with a crest elevation at MSL. Results show that such a caisson configuration enhances the structural stability of the caisson compared to an ordinary caisson.

Furthermore, the reflection performance of the two configurations were compared in terms of spectral averaged and phase resolved reflection components. The APC yielded a mean reflection coefficient about 0.5 under irregular waves whilst this value rose to the order of 0.75 for OC. Additionally, the antifer damage were evaluated during tests with a block-count based method (Yagci et al. 2004), and it was shown that the antifer damage is directly related to the total energy dissipated by the caisson. This shows, once again, that the enhancement in the reflection performance is primarily due to antifer protection layer. The observations during tests and results of previous studies point out that the mechanism of energy dissipation is due to the turbulence generated within the antifer blocks (Liu et al., 1999) and moving-restoring characteristic of the placement technique (Yagci et al., 2004).

It would also be convenient to note some of the issues about the physical modeling process within the present study. First, there was not an active wave absorption system to handle the re-

\section{References}

CEM Coastal Engineering Manual (2006) U.S. Army Corps of Engineers, Washington, D.C. reflections from the wave palette. Thus, additional differences emerged between the wave series tested in OC and APC. Anyhow, this difference was shown to be acceptable in terms of wave spectra (Figure 7). Secondly, the vertical components of wave forces emerging due to sloped superstructures of the caissons were directly decomposed into horizontal and vertical components simply by taking the relevant projections of these surface segments. However, a certain amount of reduction might be expected due to the dynamic nature of the pressures, frictional/viscous losses, etc. The only available relevant reduction factors in the literature, to the authors' knowledge, are the ones proposed by Takahashi and Hosoyamada (1994) (CEM, 2006 p. VI-5-140) which would underestimate the present situation. Thus, no correction factor was applied at this aspect for the horizontal component of frontal wave force whilst 0.5 was used for the upward or downward directed component. The last note will be on the differences between present antifer protected caisson (APC) configuration and the one tested by Takahashi et al. (1990). The latter configuration was composed of complex blocks with high interlocking capacity (Tetrapods or Dolosse) and emerged up to the crest elevation of the caisson, shielding all the frontface against impulsive pressures. Compared with the highly porous and movable placement nature and lower crest elevation of the antifer block placement, it would exhibit even a higher stability performance with a higher SF. That is why the $\lambda 1, \lambda 2$ and $\lambda 33$ coefficients are changed for APC configuration tentatively in order to fit the experimental findings.

\section{Acknowledgement}

Authors gratefully acknowledge the contributions of Dr. Oral Yağc1, Adil Akgül, Atakan Yüce and Sertaç Oruç at the modelling stage of the study.

Goda, Y. (1967) "The fourth order approximation to the pressure of standing waves," Coastal Engineering in Japan, 10, $1-11$. 
Goda, Y. (1985) "Random seas and design of maritime structures", University of Tokyo Press, Japonya.

Goda Y. (1994) "Dynamic response of upright breakwater to impulsive force of breaking wave," Coastal Engineering, 22(1,2), 135 158.

Goda Y. (2008) "Lecture notes of seminar on recent developments in coastal engineering by Prof. Y. Goda", 21-22 May 2008, METU Cultural \& Convention Centre, Ankara.

Goda Y. (2010) "Reanalysis of regular and random breaking wave statistics," Coastal Engineering Journal, 52(1), 71-106.

Kim, T-M \& Takayama T. (2003) "Computational improvement for expected sliding distance of a caisson-type breakwater by introduction of a doublytruncated normal distribution," Coastal Engineering Journal, 45(3), 387- 419.

Kirca, V.S.O (2008) "Effect of frontface configuration on the performance of vertical faced coastal structures," $\mathrm{PhD}$ Thesis, Coastal Sciences and Engineering Programme, Institute of Sci. \& Tech., Istanbul Technical University, Istanbul.

Kirca, V.S.O. \& Kabdasli, M.S. (2009) "Reduction of non-breaking wave loads on caisson type breakwaters using a modified perforated configuration," Ocean Engineering, 36, 1316-1331.

Kirca, V. S., Kabdasli, M. S., Seker, D. Z., \& Celikoyan, M. (2013) "Stability and Energy Dissipation of an Antifer Layer Protected Caisson." In The Twenty-third International Offshore and Polar Engineering Conference, ISOPE 2013, June 30-July 5, Anchorage, AL, USA.

Ling, H.I., Cheng, A. H.-D., Mohri,Y \& Kawabata, T. (1999) "Permanent displacement of composite breakwaters subject to wave impact," J. Wtrwy. Port, Coast., and Oc. Engrg., ASCE, 125(1), 1-8.

Liu, P.L.-F., Lin, P., Chang, K.-A. \& Sakakiyama T. (1999) "Numerical modeling of wave interaction with porous structures," J. Wtrwy. Port, Coast., and Oc. Engrg., ASCE, 125(6), 322-330.

NAVFAC (Naval Facilities Engineering Command) (1986) "Design Manual DM702: Foundations and Earth Structures", p. 7.2-63, Virginia.
Oumeraci, H. (1994) "Review and analysis of vertical breakwater failures-lessons learned," Coastal Engineering, 22, 3-29.

Oumeraci H. \& Kortenhaus A. (1994) "Analysis of the dynamic response of caisson breakwater," Coastal Engineering, 22(1;2): $159-183$.

Sakakiyama T. \& Liu, P.L.-F. (2001) "Laboratory experiments for wave motions and turbulence flows in front of a breakwater." Coastal Engineering, 44, 117139.

Shimosako, K, Takahashi, S. \& Tanimoto, K. (1994) "Estimating the sliding distance of composite breakwaters due to wave forces inclusive of impulsive forces," in Proceedings of 24th ICCE, ASCE: 15801594.

Shimosako, K. \& Takahashi, S. (1999) "Application of deformation based reliability for coastal structures," in proceedings of Coastal Structures '99, p.363-371, (ed.) Losada, Balkema, Rotterdam.

Sørensen, J.D. \& Burcharth, H.F. (2000) "Reliability analysis of geotechnical failure modes for vertical wall breakwaters," Computers and Geotechnics, 26, 225-245.

Takahashi., S., Tanimoto, K., \& Shimosako, K. (1990) "Wave and block forces on a caisson covered with wave dissipating blocks," Report of Port and Harbour Research Institute, Yokosuka, Japan, Vol 30, No. 4, pp 3-34 (in Japanese).

Takahashi, S., Tanimoto, K. \& Shimosako, K. (1994) "A proposal of impulsive pressure coefficient for the design of composite breakwaters," in proceedings of HydroPort'94, vol. 1., Port and Harbour Research Institute, Yokosuka, 489- 504.

Walkden, M.J., Wood, D.J., Bruce T. \& Pregrine, D.H. (2001) "Impulsive seaward loads induced by wave overtopping on caisson breakwaters," Coastal Engineering, 42, 257-276.

Wang Y, Hua L \& Dong S. (2004) "Dynamic model of vibrating-sliding-uplift rocking coupled motion and dynamic design method of caisson breakwaters," Science in China, Series E, 34(3), $564-576$. 
Wang Y., Chen N.N. \& Chi L.H. (2006)

"Numerical simulation on joint motion process of various modes of caisson breakwater under wave excitation," Communication in Numerical Methods in Eng'g, 22, 535-545.

Yagci, O., Kapdasli, S \& Cigizoglu, H.K. (2004) "The stability of the antifer units used on breakwaters in case of irregular placement," Ocean Engineering, 31, p. 1111-1127. 